- its own research assessed.

This arrangement has already run into trouble. Almost two years after announcing its decision to construct a rock laboratory, Nirex pulled out of an arrangement with the government's pollution inspectors to fund an assessment of its waste disposal plans, midway through the study.

In a report, the inspectors noted that Nirex had delayed providing key information. The Royal Society, too, noted communication difficulties between the inspectors and Nirex. Holmes, however, says that particular assessment was geared to-wards lodging a repository planning application in 1992, and ended "by mutual arrangement". Both organizations, he adds, are consulting over a fresh research assessment.

Miro Ivanovich, professor of geochemistry at the University of Reading, who has been involved in Nirex work, says future assessments must be made more transparent. He says Nirex should be asked to place its research funds under independent control. "I'm not criticizing the quality of what they [Nirex] do," he says. "But people must be convinced that there is no conspiracy."

Part of the problem stems from the shortage of independent hydrogeological expertise in the UK radioactive waste management community. Western says that both FoE and Cumbria County Council had difficulty in finding independent experts to review Nirex's evidence to the rock laboratory inquiry. "The majority of hydrogeologists working in radioactive waste management have had some contact with Nirex," says Jane Dotteridge, lecturer in hydrogeology at University College London and chair of the hydrogeology group of the Geological Society of London.

Dotteridge says that graduates from several new MSc courses in radioactive waste management could herald a change. But this is unlikely while Nirex remains the

\title{
Rock laboratory faces key questions
}

London. Before the seal is set on Sellafield in Cumbria, northwest England, as the home of Britain's first underground nuclear waste repository, Nirex will need to convince itself - and its critics that the waste poses no danger to present and future generations.

The greatest potential threat is from radionuclides finding their way back to the surface long after the cement-filled steel drums containing the waste have been corroded by groundwater seeping into the repository. Nirex needs to assess how quickly water will enter the repository and corrode the containers.

One of the most difficult tasks is to predict the fracture pattern of the rocks, and then to calculate the speed and direction of the groundwater flow. Nirex's safety assessment also needs to consider the effects of gas deposits, earthquakes and climate change - an ice age is predicted to return to Cumbria within 100,000 years.

The organization has begun to address some of these issues by drilling deep boreholes near the planned repository. It now wants to build its controversial rock laboratory, consisting of two 5-metre-diameter shafts dug 790 and 920 metres into the ground, connected to a network of tunnels.

But critics believe there is more borehole work to be done. Opposition to the

dominant funder of research.

Holmes discounts the need for any additional external reviews of Nirex's work, however, and says there "is no shortage of alternative opinions". The public inquiry for the repository will, he says, provide a good scheme centres on concerns that Nirex has not fully considered the impact on the site's hydrogeological and hydrogeochemical conditions of constructing the laboratory.

The Radioactive Waste Management Advisory Committee (RWMAC) and Friends of the Earth have pointed out that Nirex must provide evidence that building the laboratory will not disturb the natural environment that it aims to monitor. John Holmes, Nirex's director of science, says the company has commissioned four scientists to assess this issue. He says their recommendations will be published and acted upon.

In addition, the Royal Society and RWMAC have suggested that Nirex's relatively short research timetable may not yield enough data for a proper safety assessment and should be extended. Nirex plans to apply for planning permission for the repository by 1998-99. But these organizations point out that accurate data will not be obtained until environmental conditions settle down, which could take up to three years after the laboratory's construction.

Holmes says that Nirex is committed to keeping the rock laboratory open for nearly 10 years, and will walk away from the site if the results show that a Sellafield repository, as currently proposed, is potentially unsafe. E. M.

test of Nirex's arguments. He says the grilling that Nirex received at the inquiry for the rock laboratory from environmentalist groups should be ample evidence that "there is no chance that we can pull the wool over people's eyes".

Ehsan Masood

\section{US panel approves salt bed burial in New Mexico}

Washington. The United States can safely bury intermediate nuclear waste in a salt bed under southern New Mexico, provided that future generations do not try to drill for oil through the dump, according to a panel of experts convened by the National Research Council (NRC), the operating arm of the National Academy of Sciences.

Their recommendation will increase the chances that the proposed Waste Isolation Pilot Plant (WIPP) will be constructed. The Department of Energy, which wants to build the dump in order to dispose of plutonium cuttings and other debris from the nuclear weapons programme, will formally apply this week to the Environmental Protection Agency (EPA) for permission to do so.

The panel, chaired by Charles Fairhurst, a mining professor at the University of Minnesota, found that, in the absence of human disturbance, the proposed repository would successfully isolate the barrels of solid waste for at least ten thousand years. In the event of drilling or other human activity, the panel said, engineering methods are available that would minimize the chances of radioactive releases.

Plans to build the WIPP near Carlsbad, New Mexico, have been under consideration for almost twenty years, and experimental storage areas have been dug out of the salt 2,000 feet underground. The salt bed is an attractive medium for dumping because the salt is virtually impermeable to water, but will gradually close up around the waste and seal it, like a viscous fluid.

WIPP would store up to 137,000 cubic metres of the solid waste, held in 55-gallon steel drums. The total radiation inventory in the repository would be a thousand times less than at the proposed store for spent nuclear fuel at Yucca Mountain, Nevada.
Unlike Yucca Mountain, WIPP has the support of many politicians in its home state.

"In the undisturbed condition, we see no credible scenario for the release of radionuclides" from the proposed dump, says Fairhurst, pointing that the situation is different in other countries which have abandoned the idea of repositories.

The panel noted that EPA regulations assume that oil and gas drilling activity will take place over the next 10,000 years at the rate now prevalent in the surrounding area. This assumption is "highly conjectural and lacks scientific foundation," Fairhurst says.

The panel suggests that the EPA should reconsider its assumptions about drilling activity, and that the Department of Energy should continue work on techniques to increase WIPP's resilience to human disturbance, the nature of which, it concedes, is impossible to predict.

Colin Macilwain 